\title{
En weekend i geologiens tegn - ud og se med GD!
}

Geologiens Dage 2008 var en yderst velbesøgt begivenhed - her er nogle udpluk fra et par dage, hvor geologien var i centrum!

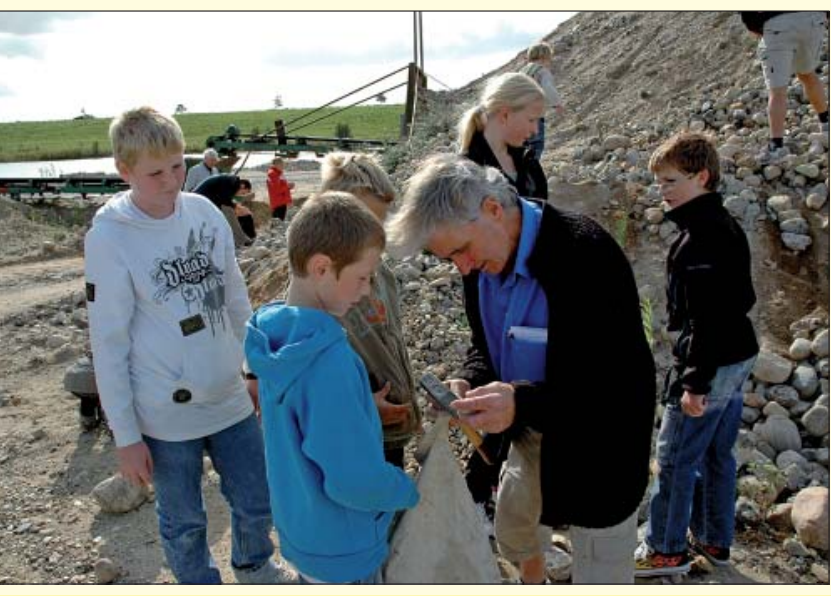

Tarup-
Davinde. Den fynske Stenklub havde stor cere af dagen med 60 voksne og 25 børn, $i$ alt 85 grester + solskin. (Foto og tekst: Carsten O. Hansen, Naturskolen Åløkkestedet)

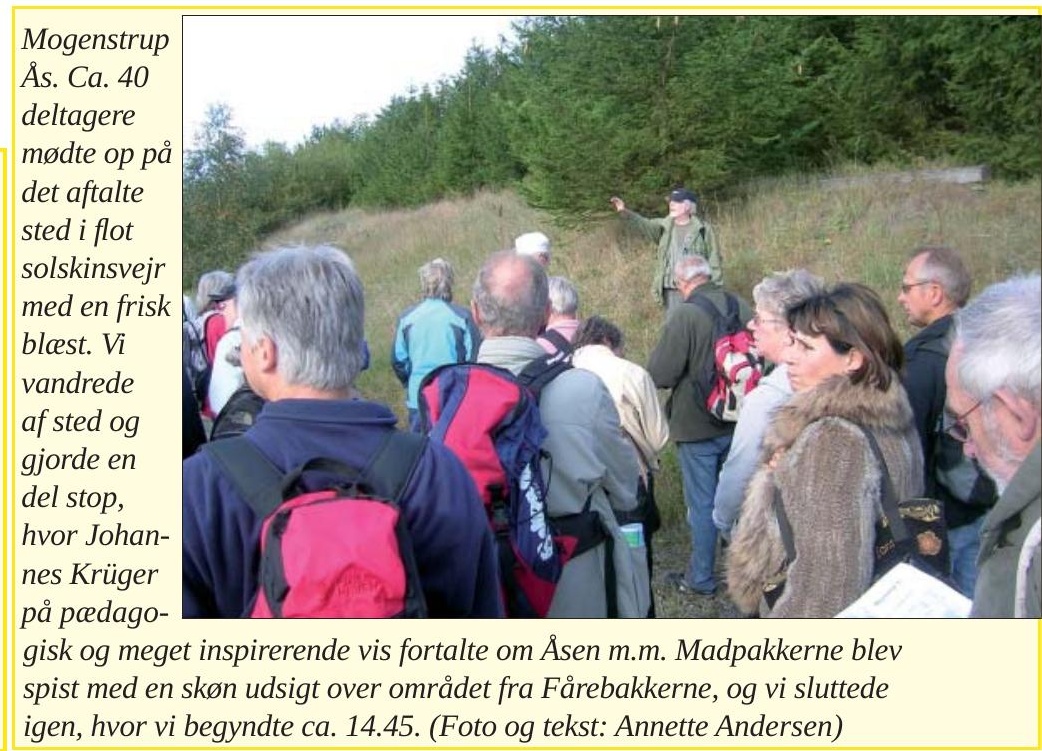

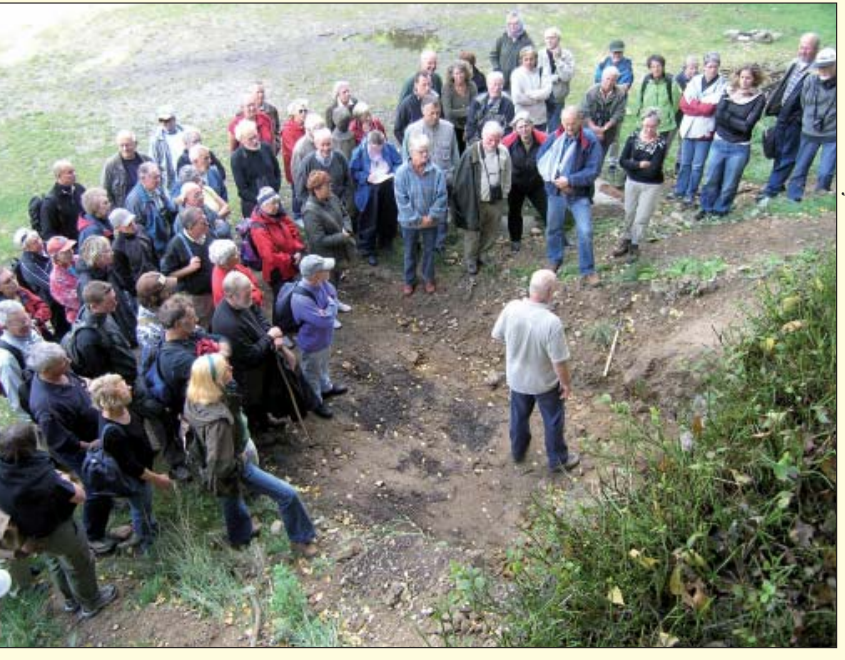

“Så fik vi vist skilt svampefolkene fra istiden." Skovfoged Svend Løw kaldte til samling før turen gik mod Gribskovs bakker og grusgraven Multebjerg. Han havde allieret sig med geolog Michael Houmark. Sammen underholdt de med geologi og planer om at gøre geologien synlig i hjertet af Gribskov. Omkring 70 mennesker deltog i turen. Første stop skete i en mregtig rydning, hvor skovfogeden fortalte, at terrcenet skulle forblive åbent, og at det åbne terrcen ville vokse i takt med, at de omkringliggende trceer bliver så store, at de kan freldes. Nceste stop var grusgraven, hvor et profil var renset op. Her fandt tilhørerne og geologen i frellesskab på meget pcedagogisk vis frem til en geologisk dannelsehistorie. Alt i alt en meget fin dag med dygtige formidlere og engagerede tilhørere. (Foto og tekst: Henrik J. Granat, Skov- og Naturstyrelsen)

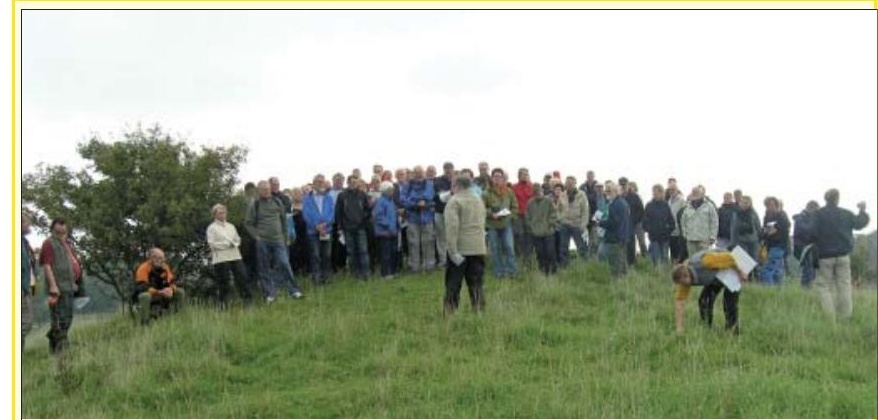

Odsherred Kommune havde inviteret til geologisk undeholdning og debat om en mulig Geopark Odsherred i Danmarks flotteste eksempel på en glacial landskabsserie. 80 mand høj vandrede op på den 82 meter høje Diesbjerg, hvor Per Smed på levende vis gennemgik stedets geologiske dannelseshistorie med sidespring til Jylland, Island. Tyskland og Poland. Herefter forklarede Nina Lemkov fra Kommunen om Odsherreds Kommunes planer om en Geopark i området. De meste interesserede vandrede ned til radiostationen ved foden af bakkerne ved vandet, for at besigtige det, der engang måske bliver geocenter. En herlig dag i godt selskab og flot vejr. (Foto og tekst: Henrik J. Granat, Skov-og Naturstyrelsen)

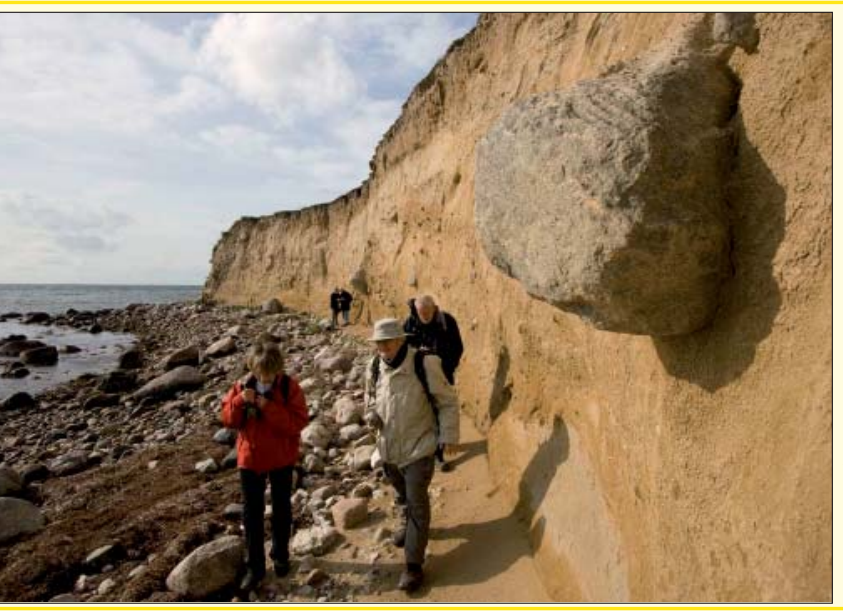

På Knudshoved Odde findes flotte kystklinter med morceneler, som er afsat af isstrømme fra syd. På billedet ses en stor granitblok. (Foto: Jakob Lautrup, copyright: GEUS; tekst: Ole Bennike)

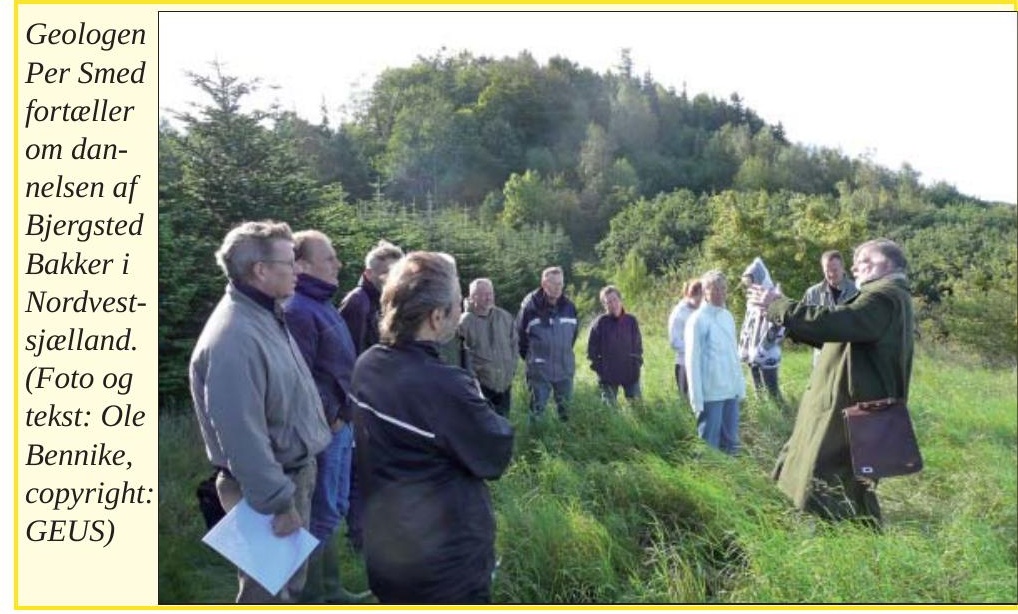

